\title{
Silicone oil in the treatment of massive preretinal retraction. I. Results in 105 eyes
}

\author{
R. H. B. GREY AND P. K. LEAVER \\ From the Retinal Unit, Moorfields Eye Hospital, City Road, London
}

SUMMARY A study of 105 eyes in which intraocular injection of silicone oil was used to treat retinal detachment with massive preretinal retraction showed that early results were encouraging, and anatomical and visual results correlated well. Operative complications had little influence on the immediate outcome, the reasons for failure being poor case selection or inadequate surgical technique. When a deterioration occurred during the postoperative period it was found to be associated with late complications, particularly cataract; redetachment occurred in only a small number (12\%) of cases.

\begin{abstract}
'And fill'd their lamps with everlasting oil to give due light ...' (Milton, 1634)

The value of intraocular silicone oil injection in the treatment of complicated retinal detachments has been reported by several authors (Cibis et al., 1962; Cibis, 1964, 1965; Watzke, 1967; Okun, 1968; Scott, 1972, 1973). However, a high incidence of late complications (Watzke, 1967; Okun, 1968) together with poor visual results (Kanski and Daniel, 1973) and reports of silicone oil toxicity (Cockerham et al., 1969; Mukai et al., 1972) have caused this technique to be abandoned in all but a few centres. Disappointing results of conventional methods and also of vitrectomy and the encouraging outcome of silicone oil injection in the management of retinal detachments associated with massive preretinal retraction prompted a careful assessment of this technique in our hands (Grey and Leaver, 1977). Because good initial results were not always maintained, further assessment of a larger series with longer follow-up was necessary.
\end{abstract}

\section{Patients and methods}

Of approximately 1500 cases undergoing retinal detachment surgery in the retinal unit at Moorfields Hospital between October 1973 and March 1978, 105 eyes in 104 consecutive patients in whom the authors used silicone oil injection for the treatment of retinal detachment with massive preretinal retraction were reviewed. A diagnosis of massive preretinal retraction was made when in our combined

Address for reprints: P. K. Leaver, FRCS, Moorfields Eye Hospital, City Road, London, EC1 opinion retinal shortening and rigidity made retinal reattachment by conventional means impossible.

Ninety-seven eyes $(92 \%)$ had previously undergone conventional treatment for retinal detachment, and $49(47 \%)$ had had more than one previous operation. In 69 eyes $(66 \%)$ an encircling buckle was already present, in 15 eyes $(14 \%)$ encirclement was undertaken at the time of silicone oil injection, but in $21(20 \%)$ encirclement was not undertaken.

The surgical technique used was that described by Cibis (1964) and modified by Okun (1968), and Scott (1972). A mean volume of $4.5 \mathrm{ml}$ of silicone oil (1000 cSt viscosity) was injected into the retrohyaloid space via the pars plana by either a screwdown or a three-ring syringe and visualised with the binocular indirect ophthalmoscope.

Assessment of visual acuity was recorded within 1 month and at yearly intervals after surgery, the Snellen chart being used where possible, but otherwise in terms of the patients' ability to count fingers, appreciate hand movements, or perceive light at $1 \mathrm{~m}$. The anatomical status of the retina was assessed by the binocular indirect ophthalmoscope. A case was judged to be anatomically successful if more than half the retina (including the posterior pole) was in apposition to the underlying pigment epithelium. The visual fields were assessed with the Goldmann perimeter before and after surgery in some cases.

\section{Results}

ANATOMICAL

Early (105 eyes). Anatomical success was recorded 
in 67 eyes within 1 month of surgery; in 38 eyes the retina was not reattached (Table 1 ).

Late ( 93 eyes). Ninety-three eyes were documented at 1 year or longer after surgery. In 51 the retina remained attached throughout the follow-up period, while in 6 late redetachment occurred (Table 2).

VISUAL

Early (105 eyes). Within 1 month of surgery an improvement in vision was recorded in 38 out of 68 phakic eyes, there was no change in 19 , and a deterioration had occurred in 11 . Of 37 aphakic eyes 20 were improved, 16 were unchanged, and 1 was worse (Table 3, Fig. 1). Of the 67 eyes in which a successful anatomical result was obtained $44(69 \%)$ showed a visual improvement (Fig. 2).

At 1 year (93 eyes). Of 61 phakic eyes assessed 1 year after surgery 22 showed an improvement over the preoperative level, 23 were unchanged, and 16 showed deterioration in vision, while in $\mathbf{3 2}$ aphakic eyes 15 were improved, 10 were unchanged, and 7 had deteriorated (Table 4).

Table 1 Early anatomical results

\begin{tabular}{|c|c|c|c|c|c|c|}
\hline \multirow[b]{2}{*}{ Success } & \multicolumn{2}{|c|}{$\begin{array}{l}\text { Phakic } \\
\text { (68 eyes) }\end{array}$} & \multicolumn{2}{|c|}{$\begin{array}{l}\text { Aphakic } \\
\text { (37 eyes) }\end{array}$} & \multicolumn{2}{|c|}{$\begin{array}{l}\text { Total } \\
\text { (105 eyes) }\end{array}$} \\
\hline & 45 & $(66 \%)$ & 22 & $(60 \%)$ & 67 & $(64 \%)$ \\
\hline Failure & 23 & $(34 \%)$ & 15 & $(40 \%)$ & 38 & $(36 \%)$ \\
\hline
\end{tabular}

Table 2 Late anatomical results

\begin{tabular}{|c|c|c|c|}
\hline & $\begin{array}{l}\text { Phakic } \\
\text { (61 eyes) }\end{array}$ & $\begin{array}{l}\text { Aphakic } \\
\text { (32 eyes) }\end{array}$ & $\begin{array}{l}\text { Total } \\
\text { (93 eyes) }\end{array}$ \\
\hline Success & $34(56 \%)$ & $17(53 \%)$ & $51 \quad(55 \%)$ \\
\hline Failure & $27 \quad(44 \%)$ & $15 \quad(47 \%)$ & $42 \quad(45 \%)$ \\
\hline
\end{tabular}

Table 3 Early visual results

\begin{tabular}{|c|c|c|c|c|c|c|}
\hline \multirow[b]{2}{*}{ Better } & \multicolumn{2}{|c|}{$\begin{array}{l}\text { Phakic } \\
\text { (68 eyes) }\end{array}$} & \multicolumn{2}{|c|}{$\begin{array}{l}\text { Aphakic } \\
\text { (37 eyes) }\end{array}$} & \multicolumn{2}{|c|}{$\begin{array}{l}\text { Total } \\
\text { (105 eyes) }\end{array}$} \\
\hline & 38 & $(56 \%)$ & 20 & $(54 \%)$ & 58 & $(55 \%)$ \\
\hline Same & 19 & $(28 \%)$ & 16 & $(43 \%)$ & 35 & $(33 \%)$ \\
\hline Worse & 11 & (16\%) & 1 & $(3 \%)$ & 12 & $(12 \%)$ \\
\hline
\end{tabular}

Table 4 Visual results at 1 year

\begin{tabular}{|c|c|c|c|c|c|c|}
\hline \multirow[b]{2}{*}{ Better } & \multicolumn{2}{|c|}{$\begin{array}{l}\text { Phakic } \\
\text { (61 eyes) }\end{array}$} & \multicolumn{2}{|c|}{$\begin{array}{l}\text { Aphakic } \\
\text { (32 eyes) }\end{array}$} & \multicolumn{2}{|c|}{$\begin{array}{l}\text { Total } \\
\text { (93 eyes) }\end{array}$} \\
\hline & 22 & $(36 \%)$ & 15 & $(47 \%)$ & 37 & $(40 \%)$ \\
\hline Same & 23 & $(38 \%)$ & 10 & $(31 \%)$ & 33 & $(36 \%)$ \\
\hline Worse & 16 & $(26 \%)$ & 7 & $(22 \%)$ & 23 & $(24 \%)$ \\
\hline
\end{tabular}

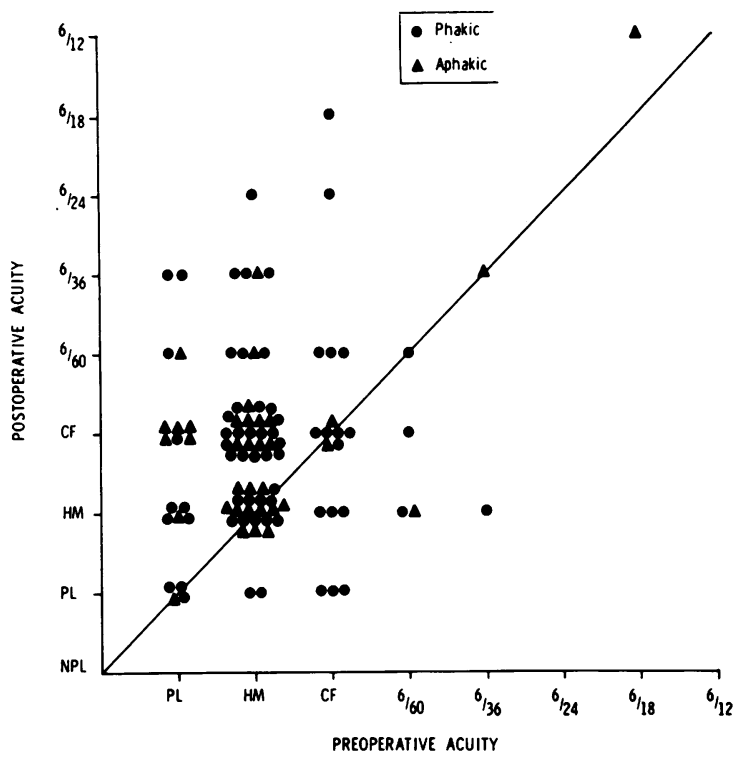

Fig. 1 Scattergram comparing the preoperative to the early postoperative acuity in 105 eyes. Points on the line show no change, those above improvement, and those below deterioration. NLP $=$ No perception of light. $P L=$ Light perception. $H M=$ Perception of hand movements at $1 \mathrm{~m} . \mathrm{CF}=$ Finger counting at $1 \mathrm{~m}$

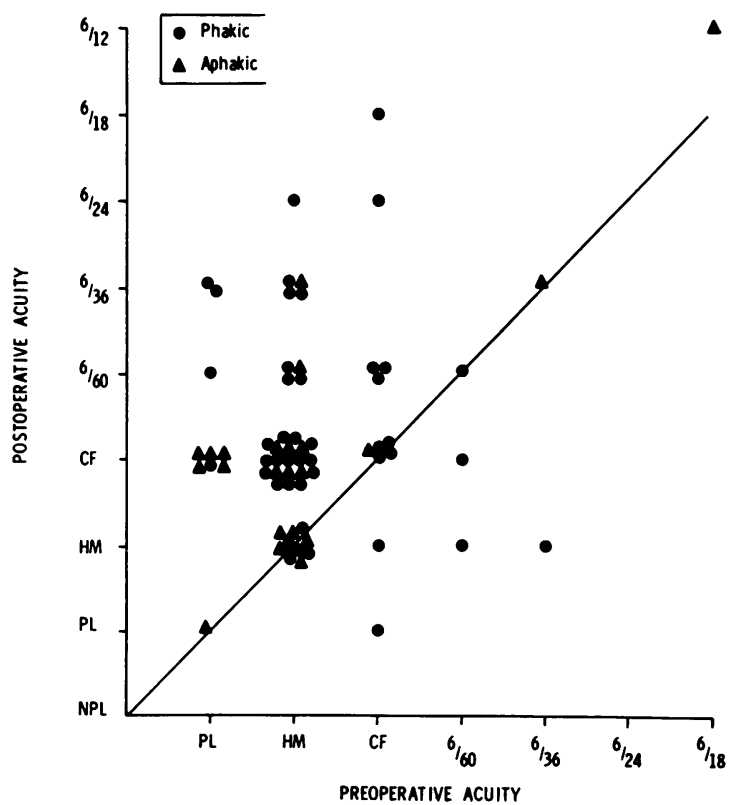

Fig. 2 Scattergram comparing the preoperaive to the early postoperative acuity in 67 eyes in which reattachment of the retina was achieved 
At 2 years ( 52 eyes). In 35 phakic eyes assessed at an interval of 2 years after surgery improvement in vision over the preoperative level was maintained in 9 , there was no change in 15 , and a deterioration was noted in 11, while in 17 aphakic eyes improvement had been maintained in 10 , there was no change in 5 , and a deterioration had occurred in 2 (Table 5).

At 3 years or longer (29 eyes). Of 20 phakic eyes in which follow-up data were available 3 or more years after surgery 6 showed an improvement over the preoperative vision, 10 were unchanged, and 4

Table 5 Visual results at 2 years

\begin{tabular}{|c|c|c|c|c|c|c|}
\hline \multirow[b]{2}{*}{ Better } & \multicolumn{2}{|c|}{$\begin{array}{l}\text { Phakic } \\
\text { ( } 35 \text { eyes) }\end{array}$} & \multicolumn{2}{|c|}{$\begin{array}{l}\text { Aphakic } \\
\text { (17 eyes) }\end{array}$} & \multicolumn{2}{|c|}{$\begin{array}{l}\text { Total } \\
\text { (52 eyes) }\end{array}$} \\
\hline & 9 & $(26 \%)$ & 10 & $(59 \%)$ & 19 & $(37 \%)$ \\
\hline Same & 15 & $(43 \%)$ & 5 & $(29 \%)$ & 20 & $(38 \%)$ \\
\hline Worse & 11 & $(31 \%)$ & 2 & $(12 \%)$ & 13 & $(25 \%)$ \\
\hline
\end{tabular}

Table 6 Visual results at 3 years or longer

\begin{tabular}{|c|c|c|c|c|c|c|}
\hline \multirow[b]{2}{*}{ Better } & \multicolumn{2}{|c|}{$\begin{array}{l}\text { Phakic } \\
\text { ( } 20 \text { eyes) }\end{array}$} & \multicolumn{2}{|c|}{$\begin{array}{l}\text { Aphakic } \\
\text { (9 eyes) }\end{array}$} & \multicolumn{2}{|c|}{$\begin{array}{l}\text { Total } \\
\text { (29 eyes) }\end{array}$} \\
\hline & 6 & $(30 \%)$ & 2 & $(22 \%)$ & 8 & $(28 \%)$ \\
\hline Same & 10 & $(50 \%)$ & 5 & $(56 \%)$ & 15 & $(52 \%)$ \\
\hline Worse & 4 & $(20 \%)$ & 2 & $(22 \%)$ & 6 & $(20 \%)$ \\
\hline
\end{tabular}

showed a deterioration, while in 9 aphakic eyes 2 were improved, 5 were unchanged, and 2 had deteriorated (Table 6). A separate assessment of those eyes for which follow-up information was available 4 years or more after surgery was not undertaken because of the small number ( 6 eyes).

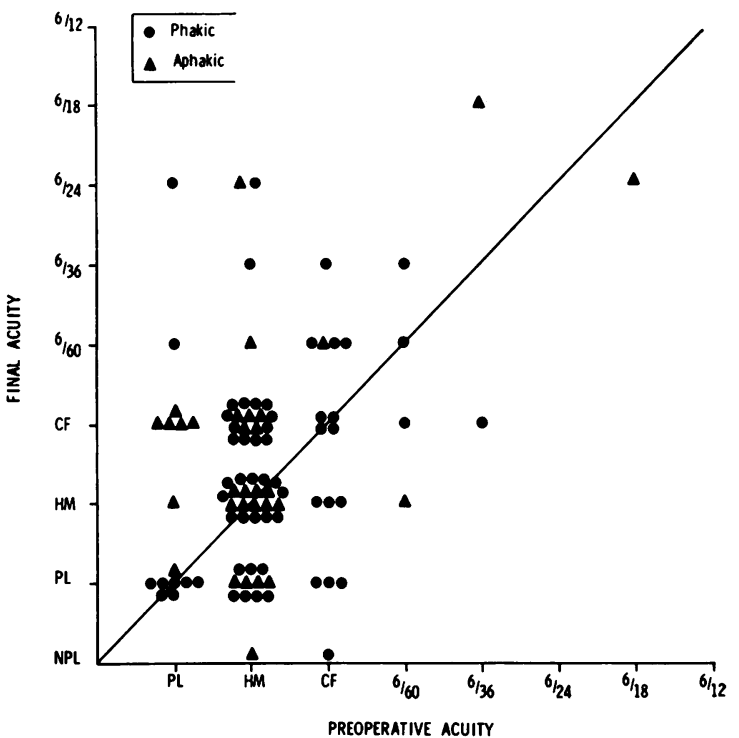

Fig. 3 Scattergram comparing the preoperative to the final acuity in 93 eyes assessed after 1 year or longer

LATE VISUAL RESULTS IN 93 EYES
Fig. 4 Histogram showing the level of acuity in 93 eyes after 1 year or longer 
Comparison of the preoperative acuity with the acuity obtained at the last follow-up visit is illustrated in Fig. 3.

Visual results in anatomically successful cases. Thirty-seven of the 51 anatomically successful cases
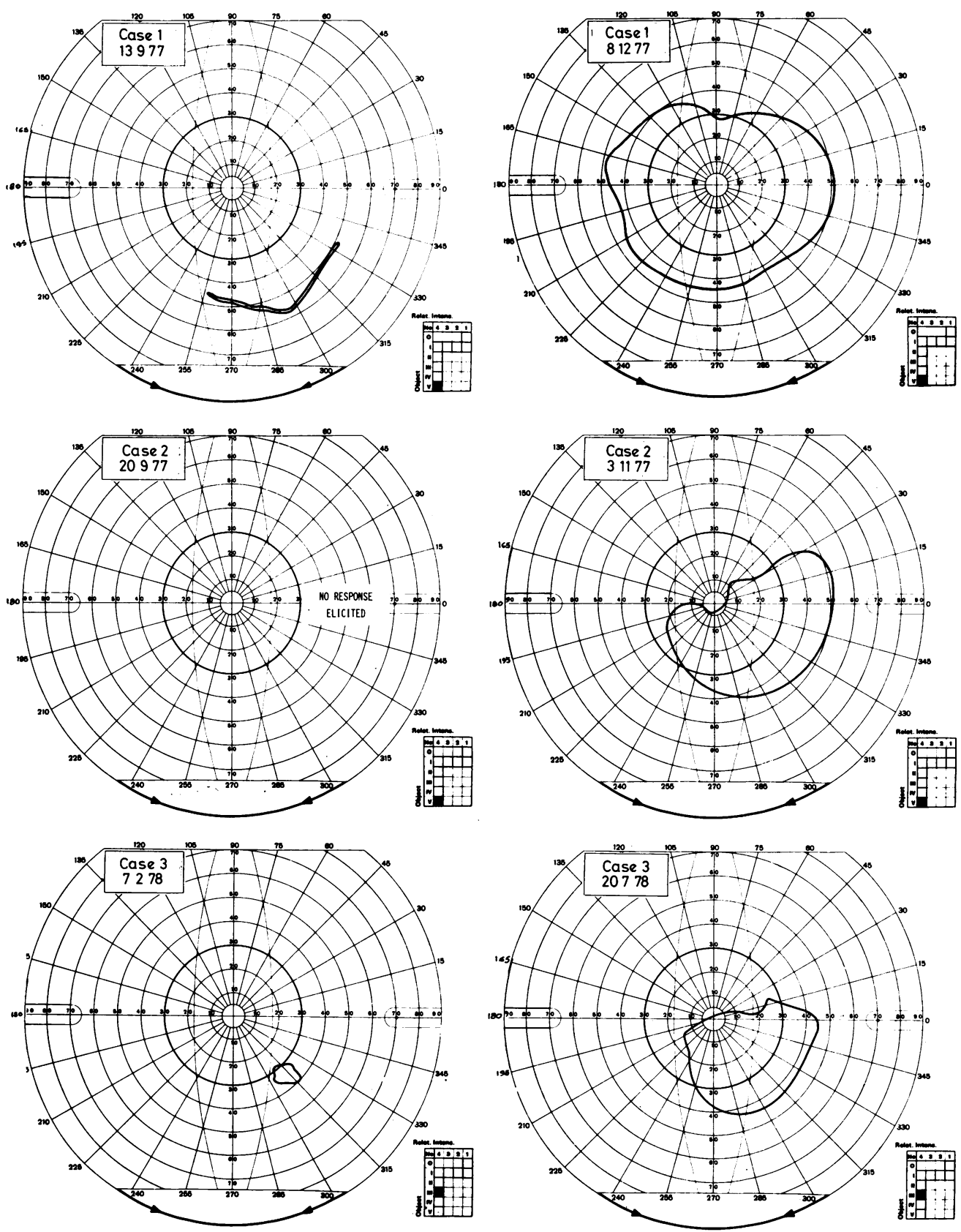

Fig. 5 Visual fields of 3 patients before and after successful reattachment of the retina. Case 3 had advanced cupping of the optic disc from chronic simple glaucoma

$(73 \%)$ maintained navigational vision after 1 year or longer compared with 6 out of 42 patients $(14 \%)$ in whom the retina was not reattached (Fig. 4). Of the 51 eyes in which the retina remained reattached throughout the follow-up period the initial result
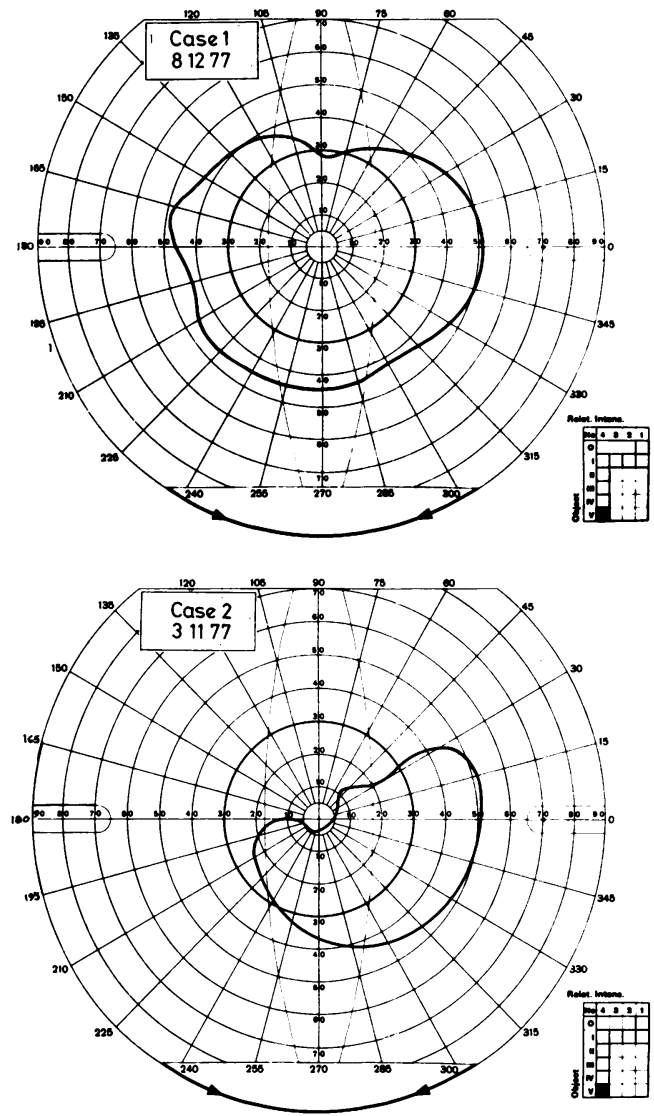
Fig. 6 Scattergram comparing the early postoperative to the final visual acuity in 93 eyes assessed after 1 year or longer. Points above the line show an improvement during the postoperative period, points on the line no change in the postoperative vision, and points below a deterioration

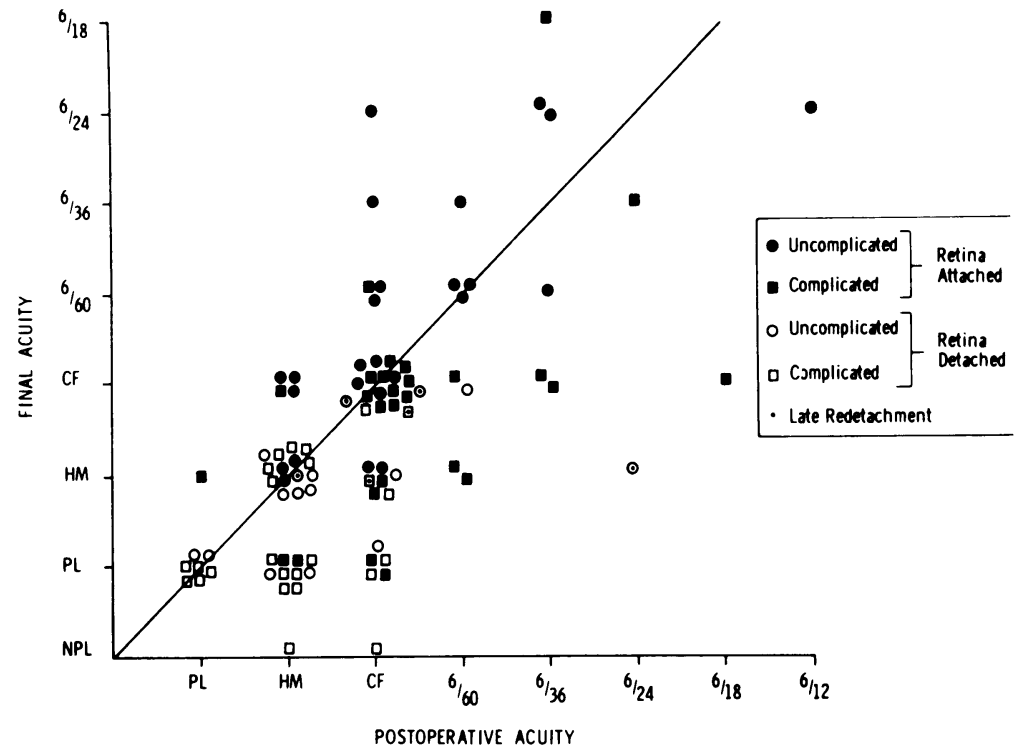

was either maintained or improved in $34(67 \%)$.

Visual fields. In all cases in which Goldmann perimetry was done after successful reattachment of the retina a marked improvement in the peripheral field was recorded (Fig. 5).

\section{SURGICAL COMPLICATIONS}

Four types of complications occurring at the time of surgery were identified: in 7 eyes silicone oil passed under the retina through a retinal break; in 11 a retinal tear was caused by the injecting needle; in 13 there was haemorrhage from retinal or choroidal blood vessels; and in 2 (both aphakic) silicone oil came forwards into the anterior chamber.

\section{Discussion}

The early results of silicone oil injection in the treatment of otherwise irreversible retinal detachments were encouraging both with regard to successful reapposition of the retina and to improvement in visual function (Tables 1 and 3). Furthermore, anatomical and visual results compared well, while the small discrepancy between them might be a reflection of irreversible retinal damage due to longstanding retinal detachment (Cleary and Leaver, 1978). Improvement in vision to a level sufficient for navigation was found to correlate well with successful reapposition of the retina with respect not only to visual acuity (Fig. 4) but also to restoration of peripheral field (Fig. 5).

Complications occurring at the time of surgery had some influence on the operative result. When oil entered the subretinal space it always did so through large retinal tears present before surgery and held open by retinal fibrosis. Small retinal tears caused by the injecting needle did not prevent retinal flattening, and retinal and choroidal haemorrhages were easily controlled by raising the intraocular pressure. When oil entered the anterior chamber at surgery, in aphakic eyes, it did so as a small globule ejected from the needle tip as it passed from the pars plana sclerotomy into the anterior hyaloid. In both cases the oil globule returned behind the pupil after operation and caused no late complication, in contrast to those cases in which forward migration of oil occurred during the postoperative period (Leaver et al., 1979).

Two reasons for deterioration of vision from the early postoperative level could be identified: persistent or recurrent retinal detachment, and development of late complications (Fig. 6). Failure to reattach the retina was due in most cases to poor case selection or inadequate surgical technique. In some cases it was impossible to predict that retinal shortening was irreversible, while in others we failed to evacuate all of the retrohyaloid and subretinal fluid. In a few cases silicone oil passed under the retina through a retinal tear at surgery (Table 7), and in a few instances late redetachment occurred in association with progressive retinal shortening (Fig. 6).

Whereas continuing visual deterioration is understandable when the retina remains detached, in anatomically successful cases it requires explanation. In one-third of the eyes in which the retina remained 
Table 7 Operative complications (26 eyes)

$\begin{array}{lr}\text { Haemorrhage } & 13 \\ \text { Subretinal oil } & 7 \\ \text { Retinal tear } & 11 \\ \text { Oil in anterior chamber } & 2\end{array}$

reattached throughout the follow-up period the vision deteriorated between the early and late assessments, usually in association with late complications (Fig. 6), in particular, cataract (Leaver et al., 1979). Indeed, a striking difference between the visual results in phakic and aphakic eyes is seen at 1 and 2 years after surgery (Tables 4 and 5) owing to the absence of this complication.

The encouragingly high incidence of successful retinal reattachment and the maintenance of visual improvement in the majority of eyes in which anatomical success was achieved confirms that silicone oil injection is an acceptable method of treating otherwise irreversible retinal detachments complicated by massive preretinal retraction. Careful assessment of results indicates that deterioration of vision due to late complications is neither as severe nor as common as previously reported, and in our opinion this method of treatment is certainly justified when the fellow eye is impaired or at risk.

We are grateful to $\mathrm{Mr}$ Lorimer Fison and the consultant surgeons at Moorfields Hospital who kindly allowed us to study the patients under their care, and to Mr David McLeod for help and encouragement in the preparation of this paper. We thank Mr T. Tarrant and the Department of Audiovisual Communications, Institute of Ophthalmology, Judd Street, London, WCl, and Mr K. Sehmi for their help with the illustrations, and Miss Christine Giffen and Miss Heather Lucas, who kindly provided valuable secretarial assistance.

\section{References}

Cibis, P. A. (1964). Vitreous transfer and silicone injections. Transactions of the American Academy of Ophthalmology and Otolaryngology, 68, 983-997.

Cibis. P. A. (1965). Recent methods in the surgical treatment of retinal detachment: intravitreal procedures. Transactions of the Ophthalmological Societies of the United Kingdom, 85, 111-127.

Cibis, P. A., Becker, B., Okun, E., and Canaan, S. (1962). The use of liquid silicone in retinal detachment surgery. Archives of Ophthalmology, 68, 590-599.

Cleary, P. E., and Leaver, P. K. (1978). Macular abnormalities in the reattached retina. British Journal of Ophthalmology, 62, 595-603.

Cockerham, W., Schepens, C. L., and Freeman, H. M. (1969). Silicone injection in retinal detachment. Modern Problems in Ophthalmology, 8, 525-540.

Grey, R. H. B., and Leaver, P. K. (1977). Results of silicone oil injection in massive preretinal retraction. Transactions of the Ophthalmological Societies of the United Kingdom, 97, 238-241.

Kanski, J., and Daniel, R. (1973). Intravitreal silicone injection in retinal detachment. British Journal of Ophthalmology, 57, 542-545.

Leaver. P. K., Grey, R. H. B., and Garner, A. (1979). Silicone oil injection in the treatment of massive preretinal retraction. II. Late complications in 93 eyes. British Journal of Ophthalmology, 63, 361-367.

Milton, J. (1634). Comus, Lines 198-199.

Mukai, N., Lee. P. F., and Schepens, C. L. (1972). Intravitreous injection of silicone: an experimental study. Annals of Ophthalmology, 4, 273-287.

Okun, E. (1968). Intravitreal surgery utilising liquid silicone: a long-term follow-up. Transactions of the Pacific Coast Otoophthalmological Society. 49, 141-159.

Scott, J. D. (1972). Treatment of the detached immobile retina. Transactions of the Ophthalmological Societies of the United Kingdom, 93, 417-423.

Scott, J. D. (1973). Treatment of massive vitreous retraction. Transactions of the Ophthalmological Societies of the United Kingdom, 93, 417-423.

Watzke, R. C. (1967). Silicone retinopiesis for retinal detachment: a long-term clinical evaluation. Archives of Ophthalmology, 77, 185-196. 